\title{
Comment on: Nathan DM, Buse JB, Davidson MB et al (2006) Management of hyperglycaemia in type 2 diabetes: a consensus algorithm for the initiation and adjustment of therapy: A consensus statement from the American Diabetes Association and the European Association for the Study of Diabetes. Diabetologia 49: 1711-1721
}

\author{
B. Schultes
}

Received: 16 August 2006 / Accepted: 21 August 2006 / Published online: 22 September 2006

(C) Springer-Verlag 2006

To the Editor:

A committee representing the American Diabetes Association (ADA) and the European Association for the Study of Diabetes (EASD) recently published a consensus algorithm for the initiation and adjustment of therapy in patients with type 2 diabetes [1].

The committee recommends lifestyle interventions aiming to improve nutritional habits (with the primary goal of losing weight) and to increase physical activity as first steps in diabetic therapy. However, while acknowledging 'the limited long-term success of lifestyle programmes to maintain glycaemic goals in patients with type 2 diabetes', the committee points out that 'a large majority of patients will require the addition of medications over the course of their diabetes'. To this purpose, the committee provides a carefully developed treatment algorithm of pharmacological therapy. Importantly, it is also stated that 'the most convincing long-term data that weight loss effectively lowers glycaemia have been generated in the follow-up of type 2 diabetic patients who have had bariatric surgery' $[2,3]$. The question therefore arises why the committee does not recommend bariatric surgery as another therapeutic option in the management of type 2 diabetic patients, especially of those with severe obesity (BMI $>35 \mathrm{~kg} / \mathrm{m}^{2}$ ).

I am well aware that most studies on the effects of bariatric surgery on diabetes suffer from severe methodo-

B. Schultes $(\bowtie)$

Interdisciplinary Obesity Center East-Switzerland,

Kantonsspital St. Gallen,

Heidenerstr. 11,

9400 Rorschach, Switzerland

e-mail: bernd.schultes@kssg.ch logical limitations, e.g. lack of data on the duration of the disease, on medications required to control glycaemia, etc. Also, for ethical reasons, most studies on bariatric surgery are only observational, rather than randomised controlled trials, thereby not meeting the criteria of providing a high level of evidence.

However, the effects of bariatric surgery on diabetes appear to be so powerful that it is questionable whether randomised controlled trials are really required before bariatric surgery can be considered a therapeutic option for patients with diabetes. Recent meta-analyses revealed a resolution of diabetes after bariatric surgery in approximately $77 \%$ and a resolution or improvement of diabetes in approximately $85 \%$ of the patients $[4,5]$.

Based on these data and my own clinical experience in caring for about 750 patients who have undergone a bariatric procedure, I am convinced that bariatric surgery currently represents the most promising option for type 2 diabetic patients to be freed from this devastating disease. I strongly believe that this therapeutic chance should not be neglected. I would, therefore, like to encourage the committee of the ADA and EASD to consider integrating bariatric surgery in their treatment algorithm for patients with type 2 diabetes.

\section{References}

1. Nathan DM, Buse JB, Davidson MB et al (2006) Management of hyperglycaemia in type 2 diabetes: a consensus algorithm for the initiation and adjustment of therapy: A consensus statement from the American Diabetes Association and the European Association for the Study of Diabetes. Diabetologia 49:1711-1721 
2. Pories WJ, Swanson MS, MacDonald KG et al (1995) Who would have thought it? An operation proves to be the most effective therapy for adult-onset diabetes mellitus. Ann Surg 222:339-350

3. Sjostrom L, Lindroos AK, Peltonen M et al (2004) Lifestyle, diabetes, and cardiovascular risk factors 10 years after bariatric surgery. N Engl J Med 351:2683-2693
4. Buchwald H, Avidor Y, Braunwald E et al (2004) Bariatric surgery: a systematic review and meta-analysis. JAMA 292: 1724-1737

5. Maggard MA, Shugarman LR, Suttorp M et al (2005) Metaanalysis: surgical treatment of obesity. Ann Intern Med 142: $547-559$ 